\title{
Elements of Psychological Maturity and Its Influence on Antisocial and Criminal Behavior
}

\author{
Sharon Casey*
}

School of Psychology, Deakin University, Australia

\begin{abstract}
Insights from developmental psychology provide a useful perspective from which to understand why young people might engage in higher levels of antisocial behavior than adults. They can also be useful in term of highlighting which aspects of development result in young people making less mature judgments. Yet despite this extensive body of knowledge, there is no psychological or legal definition of maturity that can be applied to legal decision making. Within a criminal context, investigations of adolescent immaturity have emphasized cognitive factors, influenced by the informed consent model which places a premium on factors such as "knowledge" and "competence", with an emphasis on cognitive functioning (e.g., thinking, reasoning, and understanding). This approach has been criticized for failing to adequately illustrate differences between adolescent and adult decision making. This paper reviews the notion of psychological maturity and comments on the importance of a broader assessment that includes psychosocial factors in the face of a growing trend in many jurisdictions to transfer juvenile offenders to the adult jurisdiction based on the severity of crime committed rather than their level of culpability.
\end{abstract}

Keywords: Psychological maturity, juvenile offenders, psychosocial maturity.

\section{INTRODUCTION}

The development of separate justice systems for young people $^{1}$ accused of committing criminal acts is predicated on two fundamental assumptions: First, that they are less capable of mature judgment than adults and are, therefore, considered less culpable for any offenses they might commit and, second, that they are more amenable to treatment than adults and thus more likely to benefit from rehabilitation efforts (Scott \& Grisso, 1997). While these two assumptions may seem sufficiently straightforward to facilitate the system's smooth functioning, youth justice would appear to be in a state of crisis (see Goldson, 2000; Kemshell, 2008; Pitts, 2001). According to Yates (2004), political opportunism has resulted in the politicization of both youth crime and justice, the net result of which has been profoundly distorted and conflicting policies that tend "to act on an amalgam of rationales, oscillating around and beyond the caring ethos of social services and the neo-liberal ethos of responsibility and punishment" (Muncie \& Hughes, 2002, p. 1). Public discourse and political rhetoric have demanded retribution, responsibility, and restorative justice while at the same time acknowledging the importance of human rights, the need to divert young people away from the criminal justice system, and the need for rehabilitation. It would seem, however, that social control has become the dominant paradigm in many countries (Garland, 2001). The terms "youth" and "risk" have become synonymous (Green, Mitchell \& Bunton,

*Address correspondence to this author at the School of Psychology, Deakin University, Australia; Tel: +61 35227 8715; Fax: +61 35227 78621;

E-mail: sharon.casey@deakin.edu.au

${ }^{1}$ Consistent with the tenor of the United Nations Convention on the Rights of the Child (1989), reference made in this paper to children, young people or juveniles will refer to young people under the age of 18 years.

2000), with references to "problem neighbourhoods", "incivilities", and "urban violence" increasingly dominant in the political and media landscape in response to alleged increases in youth offending (Muncie, 2008).

A risk discourse such as that which now exists can undermine social justice and erode human rights, often as a function of particular political imperatives (Goldson \& Muncie, 2006; Hendrick, 2006). Although the various international covenants ${ }^{2}$ introduced over the past two decades provide a strong foundation for ensuring the rights of young people are upheld, there remains a strong possibility in the current political climate that individual rights will be subjugated in favour of the new culture of control said to exist in many western countries (Garland, 2001). For example, while Hammarberg (2008) has noted that the "... spirit of the UN Convention on the Rights of the Child [is] to avoid criminalization and to seek family-based or other social alternatives to imprisonment" (p. 193), there is a growing trend in many jurisdictions to follow the lead of the US where young people are "adultified" (Jacobs, 2001) on the basis of crime severity or frequency and referred to the adult system for adjudication (Muncie, 2008). What seems to have been lost in this trend for more punitive sanctions and the treatment of young offenders as adults is an understanding of maturity and how this might impact on decisions regarding culpability. There is no legal definition of maturity; nor, unfortunately, does a psychological definition exist. Until the ground-breaking decision in Roper $v$. Simmons (2005) which abolished the juvenile death penalty in the US, the legal no-

\footnotetext{
2 The UN Convention on the Rights of the Child; the United Nations Standard Minimum Rules for the Administration of Juvenile Justice (Beijing Rules); the United Nations Guidelines for the Prevention of Juvenile Delinquency (Riyadh Guidelines); and the United Nations Rules for the Protection of Juveniles Deprived of their Liberty (Havana Rules)
} 
tion of maturity focused predominantly on cognitive capability (e.g., capacity for thinking, reasoning, and understanding) rather than adopting a more holistic view of developmental maturity that includes psychosocial and emotional development. The aim of this paper is draw together more recent findings which illustrate the challenges and need for a more comprehensive assessment of culpability and maturity of judgment in young people who come before the criminal justice system. This is particularly relevant in view of the current trend in many jurisdictions to transfer juvenile offenders to the adult system for adjudication.

\section{BACKGROUND}

Research in the field of developmental psychology has provided a strong body of evidence to explain why young people might engage in more antisocial behavior than adults and, more particularly, which aspects of development may be responsible for young people making less mature judgments (e.g., Cauffman, Piquero, Kimmonis, Steinberg, Chassin \& Fagan, 2007; Cauffman \& Steinberg, 2000; Cauffman, Steinberg, \& Piquero, 2005; Galambos, Macdonald, Naphtali, Cohen \& Frias, 2004; Lerner \& Galambos, 1998; Tilton-Weaver, Vitunski, \& Galambos, 2001). Based on these finding, it is now accepted that young people are more impulsive (e.g., Carroll, Hemingway, Bower, Ashman, Houghton, \& Durkin, 2006; Ramoutar \& Farrington, 2005), less risk aversive (e.g., Steinberg, 2007), have less developed problem solving skills (Antonowicz \& Ross, 2005; McMurran, Blair \& Egan, 2002), and engage in less consequential thinking than their adult counterparts (e.g., Cauffman, Shulman, Steinberg, Claus, Banich, Graham, \& Woolard, 2010). Several key findings are particularly relevant to reversing the current trend to reduce the age at which young people can be treated as adults. For example, it is now accepted that development occurs at different rates for different individuals; that rather than being invariant, development is much more fluid (i.e., skills and knowledge can accrue unevenly in different task areas rather than as a uniform increase in overall capacity); and that differences in language ability, knowledge, experience and culture affect the ages at which these various competencies emerge for different individuals (Gibbs, Basinger, Grime, \& Snarey, 2007; Jacobs \& Klaczynski, 2002; Keating, 1990; Lerner \& Galambos, 1998). Thus while the law attempts to demarcate adolescence and adulthood, this practice is clearly inconsistent with developmental science (Steinberg, Cauffman, Woolard, Graham \& Banich, 2009). As Steinberg and his colleagues have noted "Drawing age boundaries on the basis of developmental research cannot be done sensibly without a careful and nuanced consideration of the particular demands placed on the individual for "adultlike' maturity in different domains of functioning." (p. 583).

The importance of assessing multiple domains of maturity was central to the landmark decision handed down by the US Supreme Court in Roper v. Simmons (2005) which served to abolish the juvenile death penalty in that country. A 5-to-4 majority ruled in favour of raising the boundary for capital punishment from 16 to 18 years. In making their decision, the Supreme Court Justices relied heavily on an amicus curiae brief submitted by the American Psychological Association (APA, 2004) outlining relevant research into psychological development during adolescence (see Stein- berg et al., 2009). Based in part on this evidence, the Justices concluded that as compared to adults, juveniles are less culpable. In particular, it was noted that juveniles are more immature, less blameworthy and less responsible than adults; have greater difficulty controlling their impulses; are more likely to be influenced by external pressure including peer pressure; and are more vulnerable, which can be attributed in part to having less control over their environment than do adults. Attention was also given to what was perceived as differences in character between juveniles and adults: "The personality traits of the juvenile are more transitory, less fixed" (Roper v. Simmons, 2005, p. 16). An important distinction made in the Roper case is that while the performance of adolescents and adults is comparable on tests of cognitive ability (e.g., logical reasoning about moral, social, and interpersonal matters), they are not equal in terms of their psychosocial capacities (i.e., impulse control, resistance to peer influence). The remainder of this paper will review relevant developmental research which identifies the cognitive and psychosocial capacities that apply to adolescent offenders who come before the courts. In so doing, the paper will identify how differences in the developmental trajectory in these domains of impacts upon decision making.

\section{COGNITIVE ASSESSMENTS OF MATURITY}

Despite legal presumptions about the inherent immaturity of adolescents, the major focus of investigations into adolescent immaturity relies heavily on an assessment of the cognitive domain of functioning. The emphasis in this approach, which rests on the consideration of factors such as "knowledge" and "competence", is very much influenced by the informed consent model derived from research investigating the capacity of young people to give informed consent for medical procedures (see Culver, 1982; Steinberg \& Cauffman, 1996; Wadlington, 1983). The difficulty with taking a strictly cognitive approach is that by late adolescence, differences between adolescents and adults is most notable for those aged 15 years and younger (see Keating, 2004). For example, Kail's (1997) examination of age-related differences in tests of cognitive processing time, imagery skill, and spatial memory span showed that performance typically improved more rapidly in childhood than in adolescence. Hale (1990) also found that while processing speed changed as a function of age, these differences declined over a 5-year period in late adolescence: Whereas 10- and 12-year-olds were, respectively, 1.8 times and 1.5 times slower than young adults, 15-year-olds processed information at the same speed as young adults. In fact, Overton's (1990; Chapell \& Overton, 1998) research suggests there is little systematic growth in the logical abilities relevant to decision-making after the age of 16.

Given findings such as these, a number of researchers have examined whether the capacity of adolescents with respect to adjudicative competence actually differs from that of adults. While jurisdictions may differ in terms of nomenclature, the assessment of adjudicative competence is typically concerned with three primary elements: a basic comprehension of the purpose and nature of the trial process (i.e., understanding), the capacity to provide relevant information to counsel and to process information (i.e., reasoning), and the ability to apply information to one's own situation in a man- 
ner that is neither distorted nor irrational (i.e., appreciation) (see Bonnie, 1992, 1993; Bonnie \& Grisso, 2000). Not surprisingly, this body of research has revealed that while there is a significant difference in the competence-related abilities of adults and adolescents aged 15 years and younger, these differences are no longer apparent when comparing the abilities of adults and adolescents aged 16 and older (e.g., Grisso, Steinberg,Woolard, Cauffman, \& Scott et al., 2003; JacobsQuadrel, Fischhoff, \& Davis, 1993; Steinberg et al., 2009; ).

Evidence for the absence of a quantitative difference in adjudicative competence between adulthood and late adolescence was demonstrated in Grisso et al.'s (2003) comparison of adolescents in juvenile detention facilities $(\mathrm{N}=453)$ and community settings $(\mathrm{N}=474)$ and young adults in jails $(\mathrm{N}=$ 233) and the community $(\mathrm{N}=233)$ as part of the MacArthur Foundation Research Network's investigation into age differences in competence to stand trial. Adjudicative competence was assessed using the MacArthur Competence Assessment Tool-Criminal Adjudication (MacCAT-CA) ${ }^{3}$, a well-established instrument used to assess competencerelated legal capacities in adults which has also been used with adolescents in the domains of both research (e.g., Burnett, Noblin, \& Prosser, 2004; LaVelle Ficke, Hart, \& Deardorff, 2006; Warren, Aaron, Ryan, Chauhan, \& DuVal, 2003) and clinical evaluation (Ryba, Cooper, \& Zapf, 2003). Findings in the Grisso et al. study revealed significant impairment in juveniles aged 15 and younger to the extent that it would compromise their ability to serve as competent defendants in criminal proceedings. In fact, the level of impairments in one third of 11- to 13-year-olds and one-fifth of 14-15-year olds was comparable to that of seriously mentally ill adults who, based on established norms (Otto, Poythress, Edens, Nicholson, Monahan, Bonnie, Hoge, \& Eisenberg, 1998; Poythress, Nicholson, Otto, Edens, Bonnie, Monahan, \& Hoge, 1999) would be considered incompetent to stand trial. However, the competence-relevant capacities of 16and 17-year-olds did not differ significantly from those of young adults, a pattern found to be robust across groups defined by gender, ethnicity, and socio-economic status.

In a later study, Poythress, Lexcen, Grisso, and Steinberg (2006) compared the competency-relevant abilities of a sample of 16-17-year-olds youths $(\mathrm{N}=105)$ in the US who had been direct filed ${ }^{4}$ to criminal court with those of 18-24-yearold adults $(\mathrm{N}=165)$ charged in the criminal court and a separate sample of 16-17-year-olds $(\mathrm{N}=118)$ charged in juvenile court. Consistent with the earlier findings of Grisso et al. (2003) described above, very little difference was found between the 16-17-year-old defendants transferred to criminal court by direct file, 18-24-year-old criminal defendants and 16-17-year-olds charged in juvenile court on the M-CAT-CA subscales The only significant difference noted was on the Understanding subscale (assessing comprehension of courtroom procedures and rights at trial), where the

\footnotetext{
${ }^{3}$ The 22 MacCAT-CA items are grouped into three subscales: Understanding assesses comprehension of courtroom procedures and personnel and the defendant's rights at trial. Reasoning assesses the recognition of information relevant to a legal defense and the ability to process information for legal decision making. The Appreciation subscale, referring to a person's ability to recognize the relevance of information for one's own situation, assesses whether a defendant's legal decision making is influenced by symptoms of mental illness, such as delusional thinking.

${ }^{4}$ Direct file refers to the discretion of prosecutors in some US stages to file certain types of cases (usually based on offense type and/or prior offending history) in either juvenile court or criminal court.
}

direct file group performed slightly better than the adult sample (although the effect size was small $d=.38$ ). Once scores were classified according to the M-CAT-CA manual as "no impairment," "mild impairment," or "significant impairment", no significant differences were noted on the Understanding subscale $(\chi 2(4)=8.65, p>.05)$. There were significant differences in the proportion of individuals who were impaired on the Reasoning subscale $(\chi 2(4)=10.91, p<$ $.03)$ which assesses the extent to which a defendant can distinguish information relevant to constructing a defense. There was a smaller proportion of impaired individuals in the direct file group $(2 \%)$ as compared to those in the juvenile $(8 \%)$ or adult offender groups $(8 \%)$. The proportion of participants who met the criterion of "not impaired" was greater for those whose matters were directly filed (90\%) than in either the juvenile $(75 \%)$ or adult offender $(74 \%)$ groups. Based on their findings, the authors concluded that the 16-17-year-old adolescents whose matters were filed directly to the adult legal system for adjudication did not differ significantly from 18-24 year old adult criminal defendants in competence-related abilities and developmental characteristics that might potentially impact on the decision making in the legal process. In explaining the differences in impairments levels for the Reasoning subscale, the authors offer several explanations (e.g., direct-file offenders commit more serious crimes and may therefore be more sophisticated in their knowledge of the legal system) although they also acknowledge it may simply have been an anomaly in the sample. However, even if one accepts this latter explanation, what the finding does highlight is the fluid nature of cognitive development and the need for more rigorous assessment.

In light of the ruling in Roper (2005) and criticisms aimed at the APA on what was seen as its inconsistent stand on the psychological maturity of adolescents ${ }^{5}$, Steinberg et al. (2009) explored age differences in a variety of cognitive and psychosocial capacities deemed relevant to debates about the maturity of adolescents and adults, with a particular focus on how these might affect judgments of criminal blameworthiness. Issues of cognitive capacity will be considered here; the findings with respect to psychosocial maturity will be discussed in the following section. The study (The MacArthur Juvenile Capacity Study) assessed the cognitive capacity of 935 participants (ranging in age from 10 to 30 years; $M=17.84$ ) using a range of commonly used tests of cognitive skills including a measure of resistance to interference in working memory, a digit-span memory test, and a test of verbal fluency (controlling for IQ). Scores on these measures were used to create an index of general cognitive capacity. ${ }^{6}$ The analysis of age differences compared five

\footnotetext{
${ }^{5}$ In its Supreme Court amicus brief in Roper v. Simmons (2005), which abolished the juvenile death penalty, APA described adolescents as developmentally immature. In its amicus brief in Hodgson v. Minnesota (1990), which upheld adolescents' right to seek an abortion without parental involvement, APA argued that adolescents are as mature as adults. Steinberg et al. (2009) argued that because adolescents demonstrate adult levels of cognitive capability earlier than emotional and social maturity it is reasonable to assert that adolescents possess the necessary skills to make informed choices about terminating pregnancy but are less mature than adults in ways that mitigate criminal responsibility

${ }^{6}$ The authors acknowledged that the assessment of cognitive ability used in their study did not tap aspects of executive function that may be important in novel situations nor tests of higher order executive functioning (e.g., short- versus long-term consequences, coordinating affect and cognition, or balancing risk and reward). However, given executive functions such as these have both cognitive and psychosocial aspects and their aim was to maintain a distinction between general cognitive and psychosocial capacities, they considered it important not to conflate the two constructs.
} 
groups (10-11, 12-13, 14-15, 16-17, 18-21, 22-25, and 26-30 years) and revealed significant differences only in the first part of adolescence. That is, there were significant differences in general cognitive capacity between each of the first four age groups but no age differences after age 16 below. By way of comparison, provides a graphical representation of participants in each age group who scored at or above the mean level of the 26- to 30-year-olds. The findings also revealed a substantial gap between the two measures of maturity (i.e., cognitive and psychosocial) As successfully argued in the Roper case, general cognitive capacity reaches an adult level long before psychosocial maturation is complete.

\section{PSYCHOSOCIAL MATURITY}

Heavy reliance on the assessment of cognitive capacity in determining maturity has been strongly criticized for failing to adequately illustrate differences between adolescent and adult decision making at the expense of non-cognitive, psychosocial variables that influence the decision making process; that is, aspects of development and behavior that involve personality traits, interpersonal relations, and affective experiences (e.g., Grisso et al., 2003; Scott, Reppucci, \& Woolard, 1995; Steinberg \& Cauffman, 1996; Steinberg et $a l ., 2009)$. The evidence which now exists provides support for the proposition that mature judgment is in fact the "product of an interaction between cognitive and psychosocial factors, with competent decision making potentially undermined by deficiencies in either domain" (Steinberg \& Cauffman, p.251). In other words, having the cognitive skills to evaluate the costs and benefits of various courses of action will be effectively redundant if the individual is, for example, highly impulsive; similarly, the decision making capacity of a responsible and temperate individual will be ineffective if they lack the necessary cognitive skills or have limited access to relevant information.

The question, therefore, is how one defines the notion of maturity in a way which incorporates both its cognitive elements and those psychosocial factors with the inherent potential to impact on the decision making process. While a number of psychosocial factors might fall under this rubric, Steinberg and Cauffman (1996; Cauffman \& Steinberg, 1995, 2000) have argued that the majority fit within one of three categories of overarching dispositions: Responsibility (healthy autonomy, self-reliance, clarity of identity), Temperance (the ability to limit impulsivity, avoid extremes in decision making, and to evaluate situations thoroughly before acting, which includes seeking the advice of others when appropriate) and Perspective (being able to acknowledge the complexity of a situation and frame a specific decision within a larger context). In conjunction with the cognitive competence to reason abstractly, these three dispositions comprise the attributes most often associated with mature decision making as found in the literature on adolescent psychological development. An important caveat, however, is that when faced with a particular decision, the degree to which an individual demonstrates each will depend largely on two factors: the nature of the situation and the social context within which the decision is to be made. As Steinberg and Cauffman note when cautioning against the formulation of a general model of maturity of judgment, an individual may act responsibly in some situations but irresponsibly in others; be the epitome of temperance under certain condi- tions but highly impulsive under others; and demonstrate perspective in some circumstances but in others, be extremely short-sighted. Thus responsibility, temperance, and perspective are best conceived as dispositions to behave in a given way under particular conditions, rather than as fixed abilities or competencies that are displayed independent of context.

In developing their conceptualization of psychological maturity, Steinberg and Cauffman (1996; Cauffman \& Steinberg, 1995) have argued in favour of the term "judgment" rather than "decision making" as the former better encapsulates the mix of cognitive and psychosocial processes involved (i.e., factors that influence decisions) whereas the latter is more strongly associated with the cognitive domain (and in their framework refers the actual choices made). Maturity of judgment, therefore, is defined as the manner in which the "process of decision-making changes with development ... and is neither exclusively cognitive nor exclusively psychosocial but a consequence of both sets of influences (Caufman \& Steinberg, 2000, p.743). Cauffman and Steinberg first examined the relationship between these hypothesized psychosocial elements of mature judgment and subsequent decision making by comparing the responses of adolescents $\left(8^{\text {th }}, 10^{\text {th }}\right.$, and $12^{\text {th }}$ grade students) with two groups of young adults (college students aged $<21$ and $>21$ ) on measures of psychosocial maturity and a series of hypothetical decision-making dilemmas about potentially antisocial or risky behavior. ${ }^{7}$ Their findings revealed that as compared to adolescents, socially responsible decision making was significantly more common in young adults although was not found to increase to any appreciable degree after the age of 19. Moreover, given that college students under the age of 21 performed in a manner similar to their older counterparts, the researchers concluded that once the development occurring in adolescence is complete, maturity of judgment stabilizes. Higher levels of responsibility, perspective, and temperance (i.e., increased psychosocial maturity) were shown to be positively associated with more mature decision-making, regardless of age. In other words, it is psychosocial maturity rather than chronological age which is likely to be a stronger predictor of risky and/or antisocial decisions. The authors concluded that unlike cognitive development, which appears to peak by mid-adolescence, psychosocial characteristics continue to develop during late adolescence and, furthermore, that these changes are associated with a significant decline in antisocial decision-making.

There are two important limitations when drawing conclusions based on the Cauffman and Steinberg (2000) findings: First, despite the large sample $(\mathrm{N}=1000)$, it was drawn from a non-offender population and, second, the use of college students may have confounded the results. However, more recent findings from studies conducted by researchers involved in the MacArthur Foundation Research Network's investigation into age differences in competence to stand trial do offer support for the importance of psychosocial variables in the assessment of maturity. For example, in the

\footnotetext{
7 Antisocial decision-making was assessed using the Youth Decision-Making Questionnaire (Ford, Wentzel, Wood, Stevens, \& Siesfeld, 1990) which presents a set of hypothetical situations that involve choosing between antisocial and socially accepted courses of action (e.g., shoplifting versus not shoplifting). For each hypothetical situation, participants indicate how they would behave if they were confronted with such a dilemma
} 
Grisso et al. (2003) study described above, participants also completed the MacArthur Judgment Evaluation (MacJEN) which examines the potential relationship between immaturity and (a) choices made in the course of adjudication (across age groups) and (b) three psychosocial factors, namely, risk appraisal (risk recognition, risk likelihood, risk impact), future orientation, and resistance to peer influence. The findings revealed that, as compared to those aged 18 to 24, participants under the age of 18 were significantly less likely to apply relevant information to situations (e.g., assess its impact on future consequences and on others involved) and were less likely to process events in a meaningful way. Age was also significantly related to the choices made in two of three legal contexts presented ${ }^{8}$. Irrespective of IQ, the proportion of participants who opted for confession as the best choice decreased as age increased as did the proportion accepting a plea agreement, decreasing from $74 \%$ among 11 to 13 -year-olds to $50 \%$ of young adults. Participants aged 15 and younger were significantly more likely to choose options that represented compliance with authorities in all three legal contexts.

With respect to the other psychosocial variables under investigation in the study, in all three legal contexts the younger adolescents (11-13 year olds) recognized risks significantly less often, while those aged under 14 were more likely to report that risks would be serious if they occurred. Young adults, on the other hand, reported a significantly higher likelihood of risk in each of the situations. In terms of providing long-range future consequences in explaining choices, perhaps not unsurprisingly, those aged 14 and under did this significantly less often. Finally, the relationship between age and peer influence was found to vary depending on the nature of the participant's original choice. For example, in the police interrogation vignette, resistance to peer pressure was stronger for those who initially indicated they would confess as compared to those stated they would deny or remain silent (young adults were more likely to change their minds and remain silent than younger participants, who were more likely to resist peer influence and confess anyway). By contrast, resistance increased with age for those who originally stated they would remain silent. For the lawyer consultation vignette, only the original choice predicted resistance to peer influence, with participants who reported they would not fully disclose information significantly less likely to resist peer influence than those who stated they would fully disclose. Similarly, original vignette choice predicted resistance to peer influence in the plea agreement vignette: greater resistance to peer pressure was found for participants who reported they would accept the plea agreement. According to Grisso et al. (2003), their findings offer support for the claim that psychosocial immaturity has the potential to negatively impact how a young defendant performs in a way that is beyond the scope of any assessment of competency to stand trial. Moreover, their findings are consistent with those of the US Supreme Court in Roper with respect to psychosocial immaturity in adolescents; that is, the tendency for adolescents to be less risk aversive, exercise

\footnotetext{
8 The vignettes in the MacJEN pose three legal decisions common in the delinquency/criminal process: (a) responding to police interrogation, (b) disclosing information during consultation with a defense attorney (one half of the participants were administered a vignette about a public defender and one half a vignette about a privately retained attorney); and (c) responding to a plea agreement for reduced consequences in exchange for a guilty plea and testimony against other defendants.
}

for adolescents to be less risk aversive, exercise poor impulse control, and be less resistance to peer influence.

The findings from the Poythress et al. (2006) study illustrate not only age-related differences in psychosocial development but also the importance of context (see Cauffman \& Steinberg, 1995, 2000; Steinberg \& Cauffman, 1996). For example, while the three types of defendants (direct file, juvenile court, and adult court) did not differ in their decision-making responses to either the police interrogation vignette or consultation with a public defender, the juvenile group was less likely to recommend full disclosure to a private attorney and more likely to recommend only partial disclosure (a situation which may not be in their best interests). Participants in the direct file group were also more likely to accept a plea bargain, a finding that may reflect the nature of the group (i.e., offenses deemed sufficiently serious by the prosecution to warrant transfer to the adult court) rather than maturity of judgment. Age- and context-related differences are also evident when considering comparisons on the MacJEN subscales, which revealed significant between group differences on perceptions of risk likelihood and resistance to peer influence. Those in the adult offender group were significantly more likely to score higher on the measure of risk likelihood (reflecting an understanding of the severity of the situation) than either the juvenile or direct file group. Although not significantly different $(\mathrm{p}=.10)$, scores for the direct file group were higher than the juvenile court group and the effect size $(d=.30)$ was comparable to that found for adult comparisons. In other words, the influence of context (being transferred to adult court) was more apparent in the assessment of risk for direct file participants as compared to their juvenile court peers. This would seem to reflect the nature of the crimes involved (i.e., higher severity cases are direct-filed) with the potential for more severe penalties perhaps leading to greater maturity in judgment. Similarly, that resistance to peer influence was significantly higher for the direct file group than either the adult or juvenile court groups also suggests a situational influence. Follow-up analyses revealed that a larger proportion of the direct file group retained their original choice in the attorney consultation $(68.7 \%)$ and the plea agreement vignette (72.5\%) as compared to both the adult (54.4\% and 59.6\%) and juvenile court groups (52.2\% and 57.8\%).

Finally, Steinberg et al.'s (2009) analysis of age-related differences in psychosocial development demonstrates that adolescents display adult levels of cognitive capability at a much earlier stage of development than either emotional or social maturity. The test battery used in this study included measures of five capacities frequently mentioned in discussions about age differences in maturity and their relevance to legal policy: risk perception, sensation seeking, impulsivity (motor impulsivity, inability to delay gratification, and lack of perseverance), resistance to peer influence, and future orientation. Scores on the various measures were used to produce a composite score of maturity, with lower scores indicating a lesser level of maturity. According to the authors, individuals scoring relatively lower on the composite measure can be characterized as less likely to perceive dangerous situations as risky, be more impulsive, more thrill seeking, more oriented to the immediate, and more susceptible to peer influence, a description which reflects that used by Justice Kennedy in his majority opinion in the Roper. 
Age-related differences in psychosocial maturity did not emerge until mid-adolescence and, moreover, were present throughout late adolescence and into early adulthood. In fact, whereas no significant differences were found between the first four age groups (10-11, 12-13, 14-15, and 16-17 years), significant differences were noted between the 16-17-yearolds and those 22 and older, and between the 18-21-yearolds and those 26 and older. The absence of any interaction effect between age and sex indicates that this pattern was the same for males and females.

Perhaps the most important conclusion drawn by Steinberg et al. (2009) for the assessment of maturity in a legal context is that it would be imprudent "to make sweeping statements about the relative maturity of adolescents and adults, because the answer to the question of whether adolescents are as mature as adults depends on the aspects of maturity under consideration" (p.592). Their findings were consistent with the other studies reviewed in this paper: Although it is not (typically) possible to distinguish between adolescents and adults in terms of general cognitive abilities after the age of 16 , even at the age of 18, adolescent psychosocial functioning is significantly less mature than that of individuals in their mid-20s. However, given the importance of (a) context and (b) the nature of the decision that may need to made, Steinberg and his colleagues also recommend that the age boundary between adolescence and adulthood be at different chronological ages for different purposes. Based on their extensive body of work, they make a distinction between two quite different decision-making contexts: one which allows for unhurried, logical reflection and one that does not. In other words, when it is possible for the individual to engage in deliberative, reasoned decision making, with emotional and social influences on judgment minimized or mitigated, and where objective information about the costs and benefits of alternative courses of action is available, decision making for adolescents over the age of 16 is similar to that of an adult. This would seem to fit three domains: medical decision making (in conjunction with information provided by health care professionals who can also encourage the adolescent to think through any decisions before acting), legal decision making (where legal practitioners can play a comparable role to that of medical practitioners), and decisions about participating in research studies (where the consultant role is undertaken by researchers who, in turn, are guided by ethical standards and review boards). By comparison, adolescent decision making (at least until 18 years of age) is much less likely to reflect that of an adult in situations that may elicit impulsivity, involve high levels of emotional arousal or social coercion, or fail to encourage or even permit consultation with a more knowledgeable expert. Steinberg et al. argue that this latter set of circumstances more closely resembles those in which most adolescents commit crime (i.e., in groups, without premeditation); it is also typical of the decision making circumstances in situations where there appear to be immediate rewards and few obvious or immediate costs (e.g., the purchase and use of licit and illicit drugs, dangerous driving behaviors, or unprotected sex).

\section{CONCLUSION}

A legal standard for juvenile competence - and, more importantly, what constitutes competence - is yet to be for- malized. In some jurisdictions, the courts require that adolescents have the same capacities as an adult (e.g., the ability to communicate with counsel, have a rational understanding of the processes involved) while others have set a lower threshold for competence, arguing that in a juvenile court, adolescent offenders should be assessed using juvenile norms rather than being compared to adult norms (Viljoen \& Wilgrove, 2007). This level of inconsistency underpins claims that youth justice is in a state of crisis (Goldson, 2000; Kemshell, 2008; Pitts, 2001). However, as Steinberg and his colleagues note, science cannot dictate public policy but should nonetheless inform it. What sciences shows is that intellectual maturity is reached several years before psychosocial maturity. This "conclusion" is not a new one; there exists is a substantial body of research conducted over the past five decades which provide evidence to support such a claim. Moreover, the proposition is so well-established that the US Supreme Court accepted the inherent immaturity of adolescents as the basis for mitigating criminal responsibility to the extent that it barred capital punishment for crimes committed by individuals under the age of 18 , irrespective of the heinousness of the crime.

Recent changes in many jurisdictions which has resulted in the current trend to adultify juvenile offenders and place a heavier emphasis on custodial sentences (Jacobs, 2001; Muncie, 2008) reinforce the need to develop (a) a more refined definition of maturity or maturity of judgment and (b) measures that can assess across all domains of maturity (i.e., cognitive and psychosocial). This is not a simple task. As the research reviewed herein illustrates, not only do individuals develop at different rates, but development is a fluid rather than stage-like process. Moreover, an individual who displays maturity of judgment in one situation may not necessary display the same degree of maturity in another. How then does one make an assessment of whether a young person is capable of making a mature judgment and thereby conduct assessment of their level of culpability? There is now sufficient empirical evidence regarding the importance of psychosocial factors to the making of mature judgments. That body of research has also used a number of well-known measures to assess both cognitive and psychosocial factors that, potentially, impact on the extent to which an individual can be held criminally responsible for their actions. The next step is to use this information to develop evidence-based assessment tools capable of distinguishing between the type of judgment which preceded the offending behavior and then apply the appropriate set of measures to assess the maturity of that judgment. Psychology has a great deal to offer in this respect. The ability to conduct assessments has been identified as a core competency of professional psychologists (Hunsley \& Mash, 2008) and become a unique and defining feature of their professional expertise (Krishnamurthy, VandeCreek, Kaslow, Tazeu, Miville, Kerns, et al., 2004). A change in the way in which psychological maturity is assessed could begin with psychologists taken a broader approach in their assessment.

\section{REFERENCES}

American Psychological Association. (2004, July 19). [Amicus curiae brief filed in U.S. Supreme Court in Roper v. Simmons, 543 U.S. 551 (2005)]. Retrieved from http://www.apa.org/psyclaw/roper-vsimmons.pdf. 
Antonowicz, D.H., \& Ross, R.R. (2005). Social problem solving deficits in offenders. In M. McMurran, \& J. McGuire (Eds.), Social problem solving and offending: Evidence, evaluation and evolution (pp.91-102). Chichester, UK: John Wiley \& Sons Ltd.

Bonnie, R. (1992). The competence of criminal defendants: A theoretical reformulation. Behavioral Sciences and the Law, 10, 291-316.

Bonnie, R. (1993).The competence of criminal defendants: Beyond Dusky and Drope. Miami Law Review, 47, 539-601.

Bonnie, R., \& Grisso, T. (2000). Adjudicative competence and youthful offenders. In T. Grisso \& R. Schwartz (Eds.), Youth on trial: A developmental perspective on juvenile justice (pp. 73-103). Chicago: University of Chicago Press.

Burnett, D. M. R., Noblin, C. D., \& Prosser, V. (2004). Adjudicative competency in a juvenile population. Criminal Justice and Behavior, $31,438-462$.

Carroll, A., Hemingway, F., Bower, J., Ashman, A., Houghton, S., \& Durkin, K. (2006). Impulsivity in juvenile delinquency: Differences among early-onset, late-onset, and non-offenders. Journal of Youth and Adolescence, 35, 519-529.

Cauffman, E., Piquero, A.R., Kimonis, E., Steinberg, L., Chassin, L., \& Fagan, J. (2007). Legal, individual, and environmental predictors of court disposition in a sample of serious adolescent offenders. Law and Human Behavior, 31, 519-535.

Cauffman, E., \& Steinberg, L. (1995). The cognitive and affective influences on adolescent decision-making. Temple Law Review, 68, 1763-1789.

Cauffman, E., \& Steinberg, L. (2000) (Im)maturity of judgement in adolescence: Why adolescents may be less culpable than adults. Behavioral Sciences and the Law, 18, 741-760.

Cauffman, E., Shulman, E., Steinberg, L., Claus, E., Banich, M., Graham, S., \& Woolard, J. (2010). Age differences in affective decision making as indexed by performance on the Iowa Gambling Task. Developmental Psychology, 46, 197-207.

Cauffman, E., Steinberg, L., \& Piquero, A.R. (2005). Psychological, neropsychological and physiological correlates of serious antisocial behavior in adolescence: The role of self-control. Criminology, 43(1), 133-175.

Chapell, M.S., \& Overton, W.F. (1998). Development of logical reasoning in the context of parental style and test anxiety. Merrill-Palmer Quarterly: Journal of Developmental Psychology, 44, 141-156.

Culver, C. (1982). Philosophy in medicine. New York: Oxford University Press.

Ford, M., Wentzel, K., Wood, D., Stevens, E., \& Siesfeld, G.A. (1990). Processes associated with integrative social competence: Emotional and contextual influences on adolescent social responsibility. Journal of Adolescent Research, 4, 405-425.

Galambos, N.L., MacDonald, S.W.S., Naphtali, C., Cohen, A-L., \& de Frias, C.M. (2005). Cognitive performance differentiates selected aspects of psychosocial maturity in adolescence. Developmental Neuropsychology, 28(1), 473-492.

Garland, D. (2001). The culture of control. Oxford, UK: Oxford University Press.

Gibbs, J. C., Basinger, K. S., Grime, R. L., \& Snarey, J. R. (2007). Moral judgment development across cultures: Revisiting Kohlberg's universality claims. Developmental Review, 27, 443-500

Goldson, B. (Ed.) (2000). The new youth justice. Dorset, UK: Russell House Publishing.

Goldson, B., \& Muncie, J. (2006). Youth crime and justice: Critical issues. London: Sage.

Green, E., Mitchell, W., \& Bunton, R. (2000). Contextualising risk and danger: An Analysis of young people's perception of risk. Journal of Youth Studies, 3, 109-26.

Hammarberg, T. (2008). A juvenile justice approach built on human rights principles. Youth Justice, 8, 193-196.

Hunsley, J., \& Mash, E.J. (2008). Developing criteria for evidence-based assessment: An introduction to assessments that work. In J. Hunsley \& E.J. Mash (Eds.), A guide to assessments that work (pp. 3-14). New York: Oxford University Press.

Jacobs, B.J. (2001). The evolution of U.S. criminal law. Issues of Democracy, 6, 6- 15.

Jacobs, J. E., \& Klaczynski, P. A. (2002). The development of judgment and decision-making during childhood and adolescence. Current Directions in Psychological Science, 11, 145-149.

Keating, D. (1990). Adolescent thinking. In S. S Feldman \& G. R Elliot (Eds.), At the threshold: The developing adolescent (pp. 54-89). Cambridge, MA: Harvard University Press.
Kemshell, H. (2008). Risks, rights and justice: Understanding and responding to youth risk. Youth Justice, 8, 21-37.

Krishnamurthy, R., VandeCreek, L., Kaslow, N.J., Tazeu, Y.N., Miville, M.L., \& Kerns, R. (2004). Achieving competency in psychological assessment: Directions for education and training. Journal of Clinical Psychology, 80, 725-740.

LaVelle Ficke, S., Hart, K. J., \& Deardorff, P. A. (2006). The performance of incarcerated juveniles on the MacArthur Competence Assessment Tool-Criminal Adjudication (MacCATCA). The Journal of the American Academy of Psychiatry and the Law, 34, 360-373.

McMurran, M., Blair, M., \& Egan, V. (2002). An investigation of the correlations between aggression, impulsiveness, social problem-solving, and alcohol use. Aggressive Behavior, 28, 239-245.

Muncie, J. (2008). The 'punitive turn' in juvenile justice: Cultures of control and rights compliance in Western Europe and the USA. Youth Justice, $8,107-121$.

Muncie, J., \& Hughes, G. (2002). Modes of youth governance: Political rationalities, criminalisation and resistance. In J. Muncie, G. Hughes \& E. McLaughlin (Eds.), Youth justice: Critical readings (pp. 1-18). London: Sage.

Otto, R., Poythress, N., Edens, N., Nicholson, R., Monahan, J., Bonnie, R., Hoge, S., \& Eisenberg, M. (1998). Psychometric properties of the MacArthur Competence Assessment Tool-Criminal Adjudication. Psychological Assessment, 10, 435-443.

Overton W. (1990). Competence and procedures: Constraints on the development of logical reasoning. In W. Overton, Reasoning, necessity, and logic: Developmental perspectives (pp.1-32). Hillsdale, NJ: Erlbaum.

Pitts, J. (2001). The new politics of youth crime. Discipline and solidarity. London, UK: Macmillan.

Poythress, N/G., Lexcen, F.J., Grisso, T., \& Steinberg, L. (2006). The competence-realted abilities of adolescent defendants in criminal court. Law and Human Behavior, 30(1), 75-92.

Poythress, N., Nicholson, R., Otto, R., Edens, J., Bonnie, R., Monahan, J., \& Hoge, S. (1999). The MacArthur Competence Assessment ToolCriminal Adjudication: Professional manual. Odessa, FL: Psychological Assessment Resources.

Ramoutar, K.M., \& Farrington, D.P. (2006). Are the same factors related to participation and frequency of offending by male and female prisoners? Psychology, Crime and Law, 12(5), 557-572.

Roper v. Simmons, 543 U.S. 551 (2005).

Ryba, N. L., Cooper, V. G., \& Zapf, P. A. (2003). Juvenile competence to stand trial evaluations: A survey of current practices and test usage among psychologists. Professional Psychology, Research and Practice, 34, 499-507.

Scott, E., \& Grisso, T. (1997). The evolution of adolescence: A developmental perspective on juvenile justice reform. Journal of Criminal Law and Criminology, 88, 137-189.

Scott, E., Reppucci, N., \& Woolard, J. (1995). Evaluating adolescent decision making in legal contexts. Law and Human Behavior, 19, 221244

Snyder, H. N. (2005). Juvenile arrest 2003. Juvenile Justice Bulletin. Washington, DC: Office of Juvenile Justice and Delinquency Prevention.

Steinberg, L. (2007). Risk taking in adolescence: New perspectives from brain and behavioral science. Current Directions in Psychological Science, 16, 55-59.

Steinberg, L., \& Cauffman, E. (1996). Maturity of judgment in adolescence: Psychosocial factors in adolescent decision making. Law and Human Behavior, 20, 249-272.

Steinberg, L., Cauffman, E., Woolard, J., Graham, S., \& Banich, M. (2009). Are adolescents less mature than adults? Minors' access to abortion, the juvenile death penalty, and the alleged APA "flip-flop". American Psychologist, 64, 583-594.

Tilton-Weaver, L.C., Vitunski, E.T., \& Galambos, N.L. (2001). Five images of maturity in adolescence: What does "grown up" mean? Journal of Adolescence, 24, 143-158.

United Nations (1985). Standard minimum rules for the administration of juvenile justice: "The Beijing Rules". Office of the High Commissioner for Human Rights. Adopted by General Assembly Resolution 40/33, 29 November.

United Nations (1989). Convention on the rights of the child. Office of the High Commissioner for Human Rights. Adopted by General Assembly Resolution 44/25, 20 November.

United Nations (1990a). Guidelines for the prevention of juvenile delinquency: "The Riyadh Guidelines". Office of the High 
Commissioner for Human Rights. Adopted by General Assembly resolution 45/112, 14 December.

United Nations (1990b). Rules for the protection of juveniles deprived of their liberty: "The Havana Rules". Office of the High Commissioner for Human Rights. Adopted by General Assembly Resolution 45/113, 14 December.

Viljoen, J. L., \& Wingrove, T. (2007). Adjudicative competence in adolescent defendants. Psychology, Public Policy and Law, 13, 204229.

Received: March 11, 2011

Revised: May 25, 2011

Accepted: May 25, 2011

(C) Sharon Casey; Licensee Bentham Open.

This is an open access article licensed under the terms of the Creative Commons Attribution Non-Commercial License (http://creativecommons.org/-

licenses/by-nc/3.0/) which permits unrestricted, non-commercial use, distribution and reproduction in any medium, provided the work is properly cited.
Wadlington, W. (1983). Consent to medical treatment for minors: The legal framework. In G. Melton, G. Koocher, \& M. Saks (Eds.), Children's competence to consent ( pp. 57-74). New York: Plenum Press.

Warren, J. I., Aaron, J., Ryan, E., Chauhan, P., \& DuVal, J. (2003). Correlates of adjudicative competence among psychiatrically impaired juveniles. The Journal of the American Academy of Psychiatry and the Law, 31, 299-309. 